\title{
PESCO ASSIM MESMO: JUSTIFICATIVAS PARA O DESCUMPRIMENTO DO DEFESO AMBIENTAL ENTRE OS PESCADORES DO BAIRRO MAUAZINHO, EM MANAUS - AM.
}

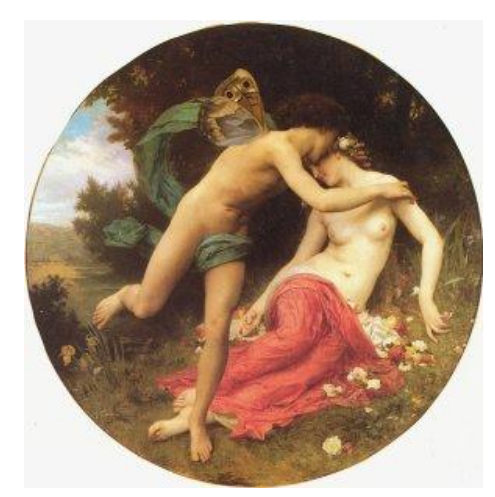

Frederico Nicolau Cesarino Katia Helena Serafina da Cruz Schweickardt

\section{Resumo}

Dentre as medidas adotadas pelo Estado para a preservação dos recursos naturais, destacase a política previdenciária específica para os profissionais da pesca, popularmente denominada seguro-defeso. Tal política proíbe a captura de determinadas espécies ao longo da temporada de sua reprodução, e assim promove-se a manutenção e renovação dos estoques da ictiofauna na costa, rios e lagos em todo o território nacional. Ocorre, no entanto, que a fraca fiscalização do Estado, aliada ao atraso no recebimento do benefício, força alguns pescadores comerciais da cidade de Manaus, em especial os pescadores residentes no bairro Mauazinho, a descumprirem esta norma ambiental. Ainda, a redução dos estoques comerciais das espécies em defeso permite a elevação dos preços de venda do produto até o consumidor final, sendo assim mais um atrativo para sua captura irregular. Sugere-se assim a necessidade de um debate entre os beneficiários do segurodefeso e o Estado, para que ocorra o correto cumprimento desta norma.

Palavras-chave: Mauazinho. Seguro-defeso. Pescador.

\begin{abstract}
Among the measures adopted by the State for the preservation of natural resources, we highlight the specific social security policy for fishing professionals, popularly known as insurance-free. This policy prohibits the capture of certain species throughout the breeding season, and thus promotes the maintenance and renewal of fish stocks on the coast, rivers and lakes throughout the national territory. However, the poor state control, coupled with the delay in receiving the benefit, forces some commercial fishermen from the city of Manaus, especially the fishermen residing in the Mauazinho neighborhood, to fail to comply with this environmental norm. Still, the reduction of commercial stocks of the closed species allows the increase of the prices of sale of the product until the final
\end{abstract}


consumer, being thus more attractive for its irregular capture. It is therefore suggested that there is a need for a debate between the beneficiaries of the insurance and the State, so that the correct compliance with this rule can occur.

Keywords: Mauazinho. Secure-off. Fisherman.

\section{Introdução}

Este trabalho objetiva a discussão a respeito da formação do bairro Mauazinho, em Manaus-AM, e do estabelecimento de uma comunidade de pescadores (artesanais e comerciais citadinos) naquela localidade, a partir da década de 1970. Pretende-se demonstrar os fatores políticos e ambientais os quais auxiliaram este migração e, especificamente, demonstrar a relação dos indivíduos desta comunidade com a política previdenciária do segurodefeso, estabelecida pelo atual Ministério da Pesca a partir da década de 1990.

De acordo com Moreira et al (2010), o pescador artesanal pratica a atividade da pesca durante todo o ano, porém o maior ou menor sucesso da atividade pesqueira depende, em muito, dos ecossistemas amazônicos, ou seja, os períodos das enchentes e cheias - dezembro a julho- e o período da vazante e seca - agosto a novembro. Dentre os produtos advindos das águas de trabalhos (WITKOSKI, 2007), a captura dos peixes é praticada, essencialmente para a subsistência e sua comercialização é insignificante.

Já o pescador comercial citadino ou monovalente, de acordo com Furtado (1993) refere-se ao indivíduo que, por conta de pressões sociais ou econômicas, migra das áreas rurais para os centros urbanos. Suas atividades de subsistência típicas da área rural amazônica (extração florestal, agricultura e pesca) deixam de existir simultaneamente ao longo do tempo de residência na cidade, passando à dedicação em apenas uma das atividades (neste caso, a pesca).

O ciclo das águas, marcado por períodos de enchentes e secas, condiciona o pescador a realizar suas atividades de captura conforme o ritmo das águas. Além disso, durante a transição para o ciclo de vazante 
(seca), ocorrem reduções na população de pescado por conta do isolamento de cardumes em lagos ou áreas que secam rapidamente. Tais fenômenos podem comprometer a reprodução das espécies e a consequente manutenção dos recursos pesqueiros. Já o período de cheia dos rios permite maior dispersão dos cardumes, maior dificuldade de captura pelo pescador, e o consequente aumento dos preços do pescado ao consumidor final do produto.

Em 1991 foi criada, no governo do presidente Fernando Collor de Mello, a modalidade especial de seguro desemprego para assegurar auxílio financeiro ao pescador que se vê privado do exercício de sua atividade, durante os períodos de defeso da atividade pesqueira para a preservação de espécie. Esta modalidade especial de benefício previdenciário é denominada popularmente como seguro-defeso.

Da maneira como é concebida, a Política do Seguro Desemprego voltada ao pescador artesanal tem como premissa básica a garantia de uma renda de subsistência ao pescador na época do defeso, considerando que este é um período em que o pescador está, por força da lei, impedido de capturar as espécies relacionadas pelo IBAMA para a temporada. Esta medida preventiva ocorre por conta da necessidade de renovação das espécies aquáticas as quais habitam, neste caso, o locus da margem esquerda do rio Negro, além do rio Solimões e seus lagos. É ainda uma tentativa de contribuição para a manutenção da sustentabilidade da atividade pesqueira artesanal e industrial em tempos futuros (RUFFINO, 2005).

Importante ressaltar que esta legislação também prevê os casos nos quais o pescador beneficiado desrespeita as determinações para não capturar as espécies migratórias que, durante certos períodos do ano, abandonam seus ambientes de origem e se deslocam ao longo das áreas de sua reprodução. Caso ocorra flagrante deste descumprimento por técnicos do IBAMA ou dos batalhões de Polícia Ambiental, o pescador flagranteado terá seu benefício cancelado e ficará impedido de recebê-lo no ano corrente 
(MOREIRA, 2010). Ocorre, no entanto, que entre os pescadores do Mauazinho muitas vezes há a transgressão dessa regra, devido à escassa fiscalização do cumprimento do defeso ambiental, como se pretende demonstrar ao longo deste trabalho.

\section{Encontros e interações entre o rural e urbano: o bairro do Mauazinho}

O Mauazinho, localizado na zona leste da cidade de Manaus, é um dos bairros localizados mais distantes do centro da cidade. Sua criação se deu em 1968 após a implantação da Zona Franca de Manaus, e seu povoamento se iniciou, de acordo com a história oficial, em 1969 após o início da construção do Porto da Ceasa (MANAUS, 2012). Em seu projeto original, o bairro teria por finalidade apenas abrigar atividades industriais e comerciais, oriundas das empresas em instalação após a criação da zona franca. No entanto, abriga cerca de trinta mil habitantes, em sua maioria trabalhadores do Polo Industrial de Manaus.

Antes da ocupação do bairro, a área fluvial compreendida entre a ilha do Marapatá e o início do encontro das águas dos rios Negro e Solimões já era utilizada como base de pesca artesanal para pescadores residentes na margem oposta ao bairro, nos municípios de Careiro Castanho, Careiro da Várzea e Autazes. Até a década de 1970, a pesca artesanal embarcada na localidade era organizada por meio de expedições de três a cinco dias, com pernoite na embarcação. O pescado capturado era vendido em Manaus em mercados longe das áreas de pesca, e após a comercialização do pescado a embarcação retornava ao município de origem.

A instalação do porto da Ceasa, da Usina Mauá e de alguns pequenos estaleiros no local inicialmente gerou aos pescadores artesanais um sentimento de ameaça às suas atividades de subsistência, pois receavam que suas atividades acabassem por expulsar os cardumes da região. À época, tais pescadores não eram organizados em sindicatos ou colônias, e 
assim não conseguiram um canal de comunicação com as empresas para expor seus questionamentos e sugestões. Felizmente, o que consideravam ameaça acabou por se tornar um fator positivo para as melhorias das condições de trabalho a este grupo de pescadores.

A criação da Avenida Solimões permitiu uma via de acesso a qual atravessava todo o bairro e o ligava ao centro da cidade. Esta avenida permitiu a instalação das atividades industriais de várias empresas ao longo da mesma, além da ocupação de áreas por migrantes de outros bairros e municípios que desejavam se empregar nas fábricas recém-criadas do Polo Industrial de Manaus. Os pescadores, durante suas atividades de trabalho no meio do rio, podiam assistir toda essa movimentação migratória a partir de suas embarcações, e ao final de 1978 um grupo de 05 famílias de pescadores decidiu se estabelecer em terrenos localizados na margem do igarapé do Mauazinho, vizinhos à Usina Mauá e bem próximos ao recéminaugurado Porto da Ceasa.

Encontraram uma situação extremamente favorável para a prática de suas atividades: à margem do igarapé, construíram um pequeno porto flutuante para suas embarcações. O custo logístico de cada expedição de pesca reduziu consideravelmente, uma vez que passaram a residir em frente ao local de captura, e a produção era comercializada no porto da Ceasa, a menos de um quilômetro de distância dali. A rede de distribuição de energia elétrica, inaugurada em 1974, permitiu a instalação de uma fábrica de gelo no bairro, e assim o pescado capturado passou a ser mais bem conservado. A segurança patrimonial das empresas às margens do rio indiretamente beneficiava os vizinhos pescadores contra a ação de assaltantes às embarcações.

Assim, a partir de 1980 outras famílias de pescadores migraram para o bairro do Mauazinho, e estima-se que em 2012 cerca de 250 pessoas residentes no local vivem da pesca artesanal. Suas residências estão 
concentradas, em sua maioria, às margens do Igarapé do Mauazinho, atrás do Cemitério Nossa Senhora das Lajes.

\section{Pescadores citadinos: definições e características.}

De acordo com Furtado (1993) o termo pescador citadino ou monovalente é referente ao indivíduo que, por conta de pressões sociais ou econômicas, migra das áreas rurais para os centros urbanos. Suas atividades de subsistência típicas da área rural amazônica (extração florestal, agricultura e pesca) deixam de existir simultaneamente ao longo do tempo de residência na cidade, passando à dedicação em apenas uma das atividades (neste caso, a pesca).

Ainda de acordo com a autora, pescadores citadinos se classificam somente como pescadores, quando questionados sobre sua atividade econômica. Habitam os centros urbanos municipais, e em sua maioria são emigrantes oriundos das áreas de várzea em busca de melhores condições de vida, porém mantendo relações com suas comunidades de origem. Juntam-se, a estes pescadores, indivíduos residentes nos próprios municípios que resolvem se converter em pescadores, por conta de motivações econômicas ou sociais diversas.

Este grupo social de pescador vive prioritariamente ou exclusivamente da pesca, e esta atividade ocupa a maior parte do tempo dos homens jovens e adultos. O produto de seu trabalho é destinado ao consumo de suas famílias e à venda. Dessa forma, a pesca é a atividade produtiva principal desse tipo de pescador, e o comércio do pescado é feito em proporções muito maiores das encontradas pelos pescadores de subsistência ou pelos próprios pescadores em suas comunidades de origem, uma vez que esta atividade era conciliada com as demais atividades rurais.

Pescadores citadinos utilizam a pesca embarcada, com tripulação e divisão de tarefas na embarcação, ou a pesca com canoa e rabeta, na qual o 
pescador geralmente trabalha sozinho. $\mathrm{Na}$ primeira modalidade, uma expedição de pesca pode durar vários dias, enquanto o "pescador rabeteiro" geralmente retorna à sua residência ao final de cada dia. A duração de uma expedição de pesca depende, principalmente, da capacidade de cada embarcação de se armazenar e conservar o produto capturado.

O grupo estudado se dedica exclusivamente à pesca durante todo o ano (exceto, em teoria, durante o período de defeso). A área de captura compreende a margem esquerda do rio Negro, ao longo da orla fluvial do bairro do Mauazinho (considerada pelos mesmos como a melhor área piscosa no perímetro urbano). Em algumas épocas do ano, geralmente entre julho e setembro, os pescadores embarcados migram suas atividades para o rio Solimões e seus lagos, por conta da ausência de cardumes com exemplares de tamanho compatível com sua comercialização.

Geralmente cada tripulação de uma embarcação de pesca é composta por membros de uma mesma família, sendo o patriarca o comandante da embarcação. Há também, no bairro do Mauazinho, indivíduos que prestam serviços avulsos a várias embarcações de pesca, geralmente nas funções de canoeiros ou lançadores de redes. Não são vinculados à nenhuma família ou embarcação, e às vezes podem prestar serviços a mais de um barco em um mesmo dia.

A área de pesca, na orla do Mauazinho, está dividida em vários lotes, denominados de campanhas, nas quais cada embarcação possui o direito de lançamento de redes de pesca ao início de cada dia. Cada campanha é demarcada com estacas de madeira e bandeiras, e cabe ao comandante da embarcação a manutenção da área da campanha nos períodos de seca do rio Negro (roçamento do capim da várzea, retirada de lixo e limpeza do solo). A campanha pode ser utilizada por outra embarcação somente se a embarcação “dona” da área não ancore sua embarcação na área até as 09h00 da manhã de cada dia. 
Os pescadores citadinos do Mauazinho são, em sua grande maioria, filiados à Colônia de Pescadores Z-12 (a qual compreende o município de Manaus). $\mathrm{Na}$ comunidade onde residem não há liderança formal entre os diversos pescadores que lá residem. Há, no entanto, alguns moradores mais antigos os quais exercem liderança natural entre os demais. Quando algum assunto importante necessita ser debatido, existe um ponto de encontro do tipo "chapéu de palha" no qual são tomadas as decisões (geralmente conflitos entre pescadores ou solicitações diversas que são encaminhadas à Colônia Z-12).

Apesar de serem filiados à colônia de pescadores e dela dependerem para muitas reivindicações, o grupo a considera um local "para se fazer política", e não considera seus dirigentes como representantes de fato. Alegam que não frequentam as reuniões da colônia por conta de sua localização distante de suas residências, e nunca houve o interesse de membros do grupo do Mauazinho de se candidatar a cargos de direção na Colônia Z-12. Alguns membros também são filiados aos sindicatos de pescadores de seus municípios de origem (principalmente Careiro da Várzea, Autazes e Careiro Castanho), o que lhes permite o acesso a algumas áreas de pesca naqueles municípios, vetadas a outros pescadores pelos membros daquelas comunidades.

\section{A pesca embarcada no Mauazinho: divisão do trabalho, divisão do produto e o peixe como mercadoria.}

A produção pesqueira na área estudada está envolvida por uma situação que transita desde aspectos relacionados ao cotidiano alimentar da população de Manaus, até diferenciadas relações de mercados as quais extrapolam o local, adotando novas lógicas na divisão do trabalho a qual envolve sua estrutura de mercado.

Uma consideração importante a ser feita é a condição do peixe enquanto mercadoria. Segundo Marx (1985), a utilidade de uma coisa faz 
dela valor de uso sendo que o valor de uso realiza-se somente no uso ou no consumo. Por outro lado as coisas também possuem uma propriedade intrínseca a si que as faz permutáveis por outras e "o que há de comum, que se revela na relação de troca ou valor de troca da mercadoria, é, portanto, seu valor" (p. 13). Com isso, a pesca apresenta outra perspectiva de mercado a qual abrange uma diferenciação na raiz das relações capitalistas de produção, que é a discussão do valor de uso e valor de troca.

Cada embarcação pesqueira possui, em sua guarnição, membros de uma mesma família em sua maioria numérica, geralmente com o chefe da família na função de "patrão", ou seja, comandante e dono da embarcação. Resumidamente, as funções laborais em uma embarcação pesqueira da comunidade estudada estão divididas da seguinte maneira:

a) Comandante da embarcação (patrão): proprietário do barco e das redes, e que conhece todas as funções no trabalho pesqueiro. Geralmente recebe o comando do barco de forma hereditária.

b) Lançador de rede: profissional especializado nesta função, com bom condicionamento físico, habilidade e força. Em alguns casos, a família não dispõe deste profissional, e o contrata no bairro do Mauazinho ou no município de careiro da Várzea.

c) Observador de cardume (olheiro): é o profissional mais respeitado da embarcação. Sua atividade consiste em fixar posto avançado e analisar o fluxo de cardumes na área da campanha. Somente após sua ordem as redes são lançadas. Geralmente o olheiro é o membro mais idoso da família, com experiência em todas as outras funções na embarcação e sem condições físicas de exercer outras funções.

d) Puxadores de rede: geralmente em quantidade de 4 a 6 por embarcação. Após a captura do cardume, são responsáveis pelo 
recolhimento da rede à embarcação, retirada e contagem dos peixes capturados. Exercem também as funções de manutenção e limpeza da embarcação. Usualmente é a primeira função exercida pelo novato no trabalho de pesca.

e) Canoeiros: responsáveis pela ligação entre a embarcação e o meio externo, transporte das redes durante o lançamento e recolhimento das mesmas, e transporte do peixe para a embarcação do atravessador. Esta função é geralmente desempenhada pelos membros mais jovens da embarcação, inclusive crianças.

Um fato peculiar e de relevante importância no estudo socioeconômico da atividade pesqueira desta comunidade, é referente à distribuição das despesas e receitas entre os membros da guarnição pesqueira, conforme o exemplo a seguir: a guarnição da embarcação Rio Mengo, composta do “patrão", lançador de rede, “olheiro”, 04 puxadores de rede e 02 canoeiros, perfazendo o total de 09 profissionais.

O comandante da embarcação é o responsável pela aquisição de todos os materiais necessários para o dia de trabalho na campanha (combustível, mantimentos, manutenção da rede e do barco, etc). Tais gastos são divididos equitativamente por todos os membros da guarnição (1/9 para cada membro). A divisão da receita da pesca, no entanto, é realizada da seguinte maneira: a embarcação e a rede passam a se tornar membros da guarnição, elevando seu número para 12 elementos. $O$ patrão, por ser proprietário de ambas, passa a representar 3/12 na divisão da receita, recebendo um valor maior ( $25 \%$ do total arrecadado) em comparação aos demais membros da guarnição (8,3\% do total arrecadado). O pescado é pago ao atravessador à vista no porto da Ceasa, e o repasse da receita da embarcação é realizado em terra, ao final do dia, e descontados os débitos da embarcação com o atravessador. O patrão da embarcação, por sua vez, 
realiza a divisão das receitas e despesas entre a tripulação somente aos sábados, pois:

\begin{abstract}
Se eu pago o pessoal todo final de dia, ele vai até a beira encher a cara de cachaça, e no dia seguinte não vem trabalhar, nem no outro, até acabar o dinheiro. Assim, sem dinheiro durante a semana, eu consigo controlar o pessoal (depoimento de R.A, dono de embarcação. Manaus, 2011).
\end{abstract}

As demais espécies capturadas são divididas entre os puxadores de rede, o lançador de rede e o observador. Por possuírem maior valor comercial agregado em relação ao jaraqui (principalmente os bagres), tais exemplares não foram repassados ao atravessador. Os pescadores os consideram como pagamento extra e os utilizam como valor de troca por outras mercadorias em terra, ou mesmo utilizados para consumo ao final do dia. Assim, o peixe não passa necessariamente por relações de mercado, mas sua função no abastecimento familiar é cumprida. Em relação a este fato, tem-se:

uma coisa pode ser valor de uso, sem ser valor de troca. É esse o caso, quando sua utilidade para o homem não é mediada pelo trabalho. (...) Quem com seu produto satisfaz sua própria necessidade cria valor de uso mas não mercadoria. (...) Para tornar-se mercadoria, é necessário que o produto seja transferido a quem vai servir como valor de uso por meio da troca (MARX, 1985, p. 14 ).

Tal particularidade do pescado representa uma forma diferenciada de suprir as demandas de abastecimento. Essa condição de apenas valor de uso reflete as relações sociais as quais compõem, ainda, o ribeirinho enquanto sujeito social que ainda não está inserido totalmente nas relações capitalistas usuais de produção. O peixe constituído de valor de uso e troca, no entanto, evidencia uma organização das forças de trabalho em torno de uma estrutura de mercado a qual viabiliza, na forma capitalista, a comercialização deste pescado. 
De acordo com Abramovay (2004), os mercados devem ser estudados sob o ângulo institucional, sociológico, histórico, como construções sociais. Deste modo, o estudo restrito às condições econômicas de mercado não é suficiente para a plena compreensão da dinâmica de um grupo social com características peculiares, como é o exemplo do grupo de pescadores do Mauazinho e suas interações sociais. $\mathrm{O}$ mercado capitalista é uma forma de interação social a qual distorce, corrompe, polui, degrada a nobreza da cooperação direta (a qual não possui relação com o dinheiro), entre outros atores.

\section{Políticas de garantia de renda ao pescador: o seguro-defeso.}

As políticas públicas em relação à proteção dos recursos pesqueiros e ao trabalhador da pesca ainda são pouco abrangentes em relação à necessidade de se preservar a ictiofauna como fonte de alimento, além da manutenção econômica do trabalhador da pesca.

Em 1991 foi criado o Seguro Desemprego aos pescadores denominados "artesanais", os quais exercem atividade de pesca, individualmente ou em regime de economia familiar, com ou sem auxílio eventual de terceiros e com a utilização de embarcações e equipamentos dispostos de tecnologia básica apenas para sua navegação e captura de pescado, em oposição às embarcações de caráter industrial. Este benefício é oriundo da Lei nº 8.287, de 1991, no governo do presidente Fernando Collor de Mello, que criou a modalidade especial de seguro desemprego para assegurar auxílio financeiro ao pescador artesanal que se vê privado do exercício de sua atividade, durante os períodos de defeso da atividade pesqueira para a preservação de espécie.

Essa lei foi revogada em 25 de novembro de 2003, e substituída pela Lei $n^{\circ} .10 .779$, a qual alterou o seguro defeso em dois itens principais: o primeiro item reduziu de três para um ano o tempo de registro do 
pescador artesanal para estar elegível ao recebimento do seguro. O segundo item procurou coibir as fraudes na concessão do benefício, ao especificar detalhadamente as exigências para a habilitação ao programa.

Em seguida, a Resolução no. 468, de 21/12/2005, do Conselho Deliberativo do Fundo de Amparo ao Trabalhador (CODEFAT), estabeleceu os procedimentos necessários para a concessão do seguro desemprego ao pescador que exerça sua atividade de forma artesanal, individualmente ou em regime de economia familiar, obedecendo a calendário instituído pelo IBAMA e conforme estabelecido pela Lei $n^{\circ}$. 10.779, de 2003 .

Para a obtenção do acesso às parcelas do seguro desemprego, concedidas a cada 30 (trinta) dias, o pescador deve comprovar que está inscrito no Ministério da Pesca há pelo menos um ano, além de apresentar o atestado da colônia de pescadores artesanais confirmando o exercício da atividade, carteira de identidade ou de trabalho, comprovante de pagamento das contribuições previdenciárias e do número de inscrição como Segurado Especial no Instituto Nacional do Seguro Social (INSS). O requerimento do beneficio deve ser realizado junto às Delegacias Regionais do Trabalho (DRTs), ao Sistema Nacional de Emprego (SINE) ou às entidades credenciadas pelo Ministério do Trabalho e Emprego (MTE).

Da maneira como é concebida, a Política do Seguro Desemprego voltada ao pescador artesanal tem como premissa básica a garantia de uma renda de subsistência ao pescador na época do defeso, considerando que este é um período em que o pescador está, por força da lei, impedido de capturar as espécies relacionadas pelo IBAMA para a temporada. Esta medida preventiva ocorre por conta da necessidade de renovação das espécies aquáticas as quais habitam, neste caso, o locus da margem esquerda do rio Negro, além do rio Solimões e seus lagos. É ainda uma tentativa de contribuição para a manutenção da sustentabilidade da atividade pesqueira artesanal e industrial em tempos futuros (RUFFINO, 2005). 
Importante ressaltar que esta legislação também prevê os casos nos quais o pescador beneficiado desrespeita as determinações para não capturar as espécies migratórias que, durante certos períodos do ano, abandonam seus ambientes de origem e se deslocam ao longo das áreas de sua reprodução. Caso ocorra flagrante deste descumprimento por técnicos do IBAMA ou dos batalhões de Polícia Ambiental, o pescador flagranteado terá seu benefício cancelado e ficará impedido de recebê-lo no ano corrente (Moreira, 2006). Ocorre, no entanto, que entre os pescadores do Mauazinho muitas vezes há a transgressão dessa regra, devido à escassa fiscalização do cumprimento do defeso ambiental, como será verificado em seguida neste artigo.

Para tanto, essa política é importante, porque ampara os pescadores e ao mesmo tempo protege os recursos pesqueiros, uma vez que proíbe a pesca nos períodos de reprodução das espécies. Nesse sentido, o Seguro Desemprego vem contribuindo para inserir os ribeirinhos pescadores nos marcos institucionais, pois muitos deles não possuem documentação, portanto, existência civil. Para ter acesso ao benefício, é necessário entrar no mundo da documentação que lhes confere rosto e fisionomia.

Além disso, a política do Seguro Desemprego estimula a criar o que se pode chamar de uma consciência ambiental de preservação dos peixes, pois ao proibir a pesca no período do Defeso contribuem para a preservação da complexa e rica biodiversidade amazônica. Centramos nossa atenção nesta comunicação para os pescadores do setor artesanal por ser o menos privilegiado em toda a história da construção das políticas públicas direcionadas à exploração pesqueira no Brasil e, em particular, na Amazônia. 


\section{(Des)cumprimento do defeso pelos pescadores do bairro Mauazinho.}

Em um espaço amostral de 06 embarcações estudadas durante o período de defeso entre novembro de 2011 e março de 2012, verificou-se que $100 \%$ das embarcações, em algum momento, descumpriu a regra de preservação. O defeso compreendeu a proibição da captura das espécies pirarucu, jaraqui, tambaqui, matrinxã, pirapitinga, sardinha, pacu, aruanã e mapará. Foi constatado que as infrações ocorriam nas seguintes configurações:

a) As espécies matrinxã, tambaqui e pacu são facilmente desenvolvidas em cativeiro, sendo comum sua criação em fazendas de psicultura na área rural de Manaus. Deste modo, o saldo da captura é repassado a atravessadores que também comercializam espécies produzidas por psicultores, e assim ocorre uma "legalização" dos exemplares capturados na natureza junto ao consumidor final, com toda a devida documentação.

b) Cardumes de pacu e jaraqui, e exemplares de aruanã são capturados junto às espécies permitidas, e caso a embarcação verifique que não há indícios de fiscalização, não as devolvem ao rio e as comercializam junto a proprietários de restaurantes de Manaus, os quais realizam sua compra no período noturno, no qual a fiscalização é menos provável de acontecer.

c) Uma única embarcação alegou realizar suas ações de captura especificamente para as espécies em defeso. Como justificativa, seu comandante mencionou que o valor comercial de tais espécies neste período chega a ser quatro vezes maior, em comparação ao restante do ano. A comercialização é realizada junto a atravessadores os 
quais já possuem clientes para o produto capturado, e o saldo de exemplares capturados é de aproximadamente quatro mil unidades ao dia. O comandante ainda alegou que arrisca esta captura por conta da falta de fiscalização, além do fato do valor do segurodefeso recebido mensalmente não ser suficiente para suprir suas necessidades básicas familiares.

A principal justificativa para o descumprimento da proibição da pesca no período de defeso é, de acordo com os pescadores, a demora no recebimento das parcelas do seguro. Verificou-se, durante esta pesquisa, que geralmente os pescadores dão entrada na documentação necessária para o recebimento do benefício tão logo inicia o período de defeso, e não antecipadamente. Alegam que, antes de janeiro, ainda estão em período de atividade laboral e, por conta da natureza de seu trabalho, não dispõem de tempo livre para tais atividades burocráticas. Deste modo, o atraso na entrada dos documentos necessários junto ao Ministério do Trabalho faz com que a primeira parcela do seguro não seja creditada logo no mês de janeiro. Sem dinheiro, são forçados a pescar clandestinamente enquanto ainda há peixe a ser capturado e clientela disposta à sua aquisição. Em fevereiro geralmente não há incidência de exemplares de porte compatível com sua comercialização, e coincidentemente o pescador recebe simultaneamente duas parcelas (janeiro e fevereiro) do seguro-desemprego. Assim, o conjunto de condições força o pescador artesanal a cumprir a regra de preservação.

Ocorre, no entanto, que o descumprimento do período de defeso não é regra entre as embarcações pesqueiras baseadas no bairro do Mauazinho. Nos períodos de defeso entre os anos de 2010 e 2012, verificou-se que a maioria dos profissionais dedicados à pesca artesanal, e residentes no bairro do Mauazinho, se dedicava a atividades econômicas diversas, tais como: 
a) Agricultura e pecuária de subsistência: o período de defeso coincide com períodos de seca nas comunidades de origem de vários pescadores estudados, sendo tais comunidades localizadas, em sua maioria, nos municípios de Careiro Castanho e Careiro da Várzea. O solo resultante das áreas afetadas pela vazante do rio Solimões tornam-se extremamente férteis e o período é aproveitado para a colheita de milho, mandioca, feijão, verduras diversas, além do abate de gado bovino. Verificou-se que a produção é praticamente toda destinada ao consumo familiar e estocada em Manaus. Algum excedente é comercializado ou trocado por outros produtos na área da Ceasa na capital.

b) Trabalho em embarcações da Marinha Mercante ou serviços portuários: verificou-se que alguns pescadores também possuíam habilitação profissional para trabalho de marinha. Tais pescadores aproveitam-se desta vantagem (aliada à falta permanente de pessoal qualificado para serviços de marinha na área do porto da Ceasa) para realizar serviços temporários em embarcações de transporte de carga e/ou passageiros. Também é verificado, não somente nos período de defeso, pescadores que trabalham como estivadores, pilotos de catraia ou agenciadores de passeios turísticos em embarcações de pequeno porte.

c) Comércio na praia do Mauazinho: o período de férias escolares coincide com o período de defeso e a formação de faixa de praia em frente ao Cemitério Nossa Senhora das Lajes, a poucos metros da área de residência de parte do grupo de pescadores estudado. A faixa de praia se transforma em balneário recreativo durante $\mathrm{o}$ período, e assim 03 famílias de pescadores possuem estabelecimentos comerciais temporários na praia. Comercializam 
principalmente bebidas alcoólicas, além de refeições a materiais de banho (toalhas, bronzeadores, entre outros).

Em relação aos patrões de embarcações pesqueiras, independente se os mesmos cumprem ou não o período de defeso, uma atividade em comum é realizada nas semanas finais deste período: a manutenção de suas embarcações e materiais de pesca. A pesca artesanal na Amazônia ainda utiliza, em suas embarcações, as mesmas tecnologias navais do início do Século XX, e que demandam de ações de manutenção periódicas para manterem-se em bom funcionamento.

As embarcações dos pescadores do Mauazinho são, em sua totalidade, construídas em madeira e sua propulsão é através da utilização de motor a óleo Diesel, montado no centro da embarcação e com comando de proa. O lançamento de redes é feito por canoas de madeira com propulsão a remo, e a localização dos cardumes a serem capturados é realizada por um pescador experiente nesta função. Embarcações modernas de pesca comercial são construídas em alumínio e aço naval, com sistemas de propulsão comandados eletronicamente, e dotadas de sistema de localização de cardumes por sonar, câmaras frigoríficas para conservação de pescado, sistemas automáticos de lançamento e recolhimento de redes.

Para a confecção deste trabalho de pesquisa, foi acompanhada a manutenção anual da embarcação Rio Mengo, realizada entre 26 de janeiro e 18 de fevereiro de 2012. De forma resumida, verificou-se a realização dos seguintes serviços de manutenção: substituição de pedaços de madeira danificados pela ação do tempo, realinhamento do motor Diesel, impermeabilização da embarcação com aplicação de manta asfáltica no casco e convés, revisão da instalação elétrica, e recuperação do conjunto de redes de pesca. Tais serviços foram realizados pelo próprio comandante da embarcação, com exceção dos serviços de eletricidade (realizados por eletricista contratado) e a recuperação das redes de pesca, coordenada pela esposa do comandante e auxiliada por outras mulheres da mesma família. 


\section{Considerações finais}

Os recursos pesqueiros são fundamentais para a manutenção da vida das populações que tradicionalmente habitam a região amazônica, e sempre tiveram papel essencial na formação da identidade e cultura de tais povos. O pescado é, desde o período pré-colonial, a principal fonte de proteínas do homem amazônico tradicional e, atualmente, o mesmo apresenta não somente um valor agregado econômico a quem o captura e comercializa, mas também um enorme valor de uso e de preservação de identidades e culturas.

A pesca é uma atividade secularmente desenvolvida, a qual envolve saberes adquiridos pelo lidar diário com o meio ambiente. Envolve também relações de parentesco, solidariedade e companheirismo, assim como um sistema econômico divergente do capitalismo tradicional. Além disso, está estritamente ligada aos ritmos dos fenômenos naturais, como as fases da lua, cheias e vazantes dos rios, ciclos reprodutivos dos peixes e estações do ano.

Populações ribeirinhas que migram do ambiente rural para o ambiente urbano acabam sendo absorvidas por conceitos capitalistas, apesar de não deixarem de manter seu capital social original. Passam a viver em constante conflito entre o tradicional e o moderno, rural e urbano, valor de uso e valor de troca; e adquirem identidade própria. No caso dos pescadores citadinos residentes no bairro do Mauazinho, este conflito pode ser evidenciado, por exemplo, na constante afirmação de pertencimento às suas comunidades de origem de suas famílias (mesmo entre os pescadores já nascidos em Manaus), ou na utilização do pescado como moeda de troca por outros produtos, na área urbana do bairro.

Nos últimos anos os impactos negativos sobre o setor pesqueiro têm sido cada vez mais intensos, uma vez que o crescimento populacional urbano e o maior acesso das populações ao ideal consumista moderno 
afastam cada vez mais o homem do conceito de preservação da natureza. Obtém-se assim um quadro caracterizado pela degradação ambiental, desigualdades sociais e econômicas, e a consequente crise ambiental. No caso da pesca, sua atividade intensa e em crescimento, sem reposição das populações da ictiofauna, aliada à poluição das áreas de pesca pela atividade urbana, permite a redução gradativa dos cardumes e o consequente impacto às famílias que dependem da pesca artesanal ou comercial.

Deste modo, o aumento do número de pescadores em suas diversas modalidades, da demanda de peixe, da frota pesqueira e os demais fatores forçaram o Estado a assumir a responsabilidade da manutenção dos cardumes e da contenção de sobrepesca, através de políticas de preservação ambiental e fiscalização das atividades dos pescadores. Tais políticas públicas estão caracterizadas principalmente na criação do período de defeso ambiental, no qual algumas espécies são proibidas de serem capturadas para a renovação do quantitativo populacional. Como compensação econômica ao pescador, lhe é ofertado um abono previdenciário em parcelas mensais, enquanto durar o período, e denominado seguro-defeso.

Entretanto, observa-se na Amazônia a ineficácia do poder público na fiscalização e controle da utilização dos recursos da ictiofauna fluvial e lacustre. Com dimensões continentais e labirintos de rios, igarapés e lagos, a região amazônica torna-se alvo fácil para infratores ambientais, em número essencialmente superior ao de agentes do Estado incumbidos do monitoramento de toda a área a ser fiscalizada.

Percebe-se que o não cumprimento do período de defeso se dá em virtude de os pescadores citadinos e comerciais possuírem uma racionalidade produtiva diferente da racionalidade do pescador de subsistência (o qual possui outras fontes obtenção de renda e alimento), além de formas diversas de percepção do recurso pesqueiro e da preservação ambiental. Para eles, o pescado adquire um valor de troca, 
destinado ao mercado consumidor de Manaus, e deste modo necessitam trabalhar enquanto for possível, durante todo o ano e em grandes quantidades. Há assim um confronto com a racionalidade produtiva dos pescadores de subsistência, os quais utilizam o pescado quase exclusivamente para o sustento familiar, caracterizado como um valor de uso em contraposição ao valor de troca.

Aliado às necessidades capitalistas dos pescadores citadinos residentes no bairro do Mauazinho, existe a burocracia e lentidão nos processos previdenciários, que por motivos diversos geram atrasos nos pagamentos das parcelas do seguro-defeso ao pescador, tornando-se mais um motivo para o mesmo cometer infrações ambientais com a justificativa da manutenção econômica de sua unidade familiar.

Este contexto exige a adequação das políticas públicas ambientais para cada modalidade pesqueira na Amazônia, e assim permitir uma contribuição efetiva na melhoria das condições de vida dos pescadores citadinos nos períodos de defeso, além da preservação da ictiofauna. Também se faz necessária a capacitação dos profissionais de pesca monovalentes em relação ao manejo dos recursos naturais, além da capacitação em outras atividades econômicas complementares à pesca, nos períodos de defeso. Finalmente, uma maior presença fiscalizadora do Estado, aliada à desburocratização, é essencial para a correta utilização dos recursos.

\section{Referências}

ABRAMOVAY, R. Entre Deus e o Diabo: mercado e interações humanas nas ciências sociais. In: Tempo Social: Revista de Sociologia da USP, 2004.

FURTADO, L. G. Pescadores do rio Amazonas: um estudo antropológico da pesca ribeirinha numa área amazônica. Belém: Museu Paraense Emílio Goeldi, 1993.

MALDONADO, S. Pescadores do mar. São Paulo: Editora Ática, 1986. 
MANAUS, Prefeitura Municipal. Bairros de Manaus. Disponível em www.pmm.am.gov.br. Acesso em 21 de março de 2011.

MARX, K. O Capital. São Paulo: Abril Cultural. Coleção os Economistas, 1985.

MOREIRA, H et al. O Seguro Defeso do Pescador Artesanal: políticas públicas e o ritmo das águas na Amazônia. Trabalho apresentado no VIII Congreso Latinoamericano de Sociología Rural, Porto de Galinhas, 2010. Disponível em: http://www.alasru.org/wp-content/uploads/2011/07/GT9-HelaneMoreira.pdf. Acesso em 21 de julho de 2012.

RAMALHO, C. N. Na busca dos mares dos direitos e da sustentabilidade: mulberes pescadeiras e participação política em Pernambuco (1970-1990). Recife, 2009.

ROCHA, M. Mulheres, manguezais e a pesca no estuário do Rio Mamanguape, Paraíba. 121f. Dissertação (Mestrado em Desenvolvimento e Meio Ambiente)- Programa Regional de Pós-Graduação em Desenvolvimento e Meio Ambiente, Universidade Federal da Paraíba. João Pessoa, 2010.

RUFFINO, M. L. Gestão do uso dos recursos pesqueiros na Amazônia. Manaus: ProVárzea, IBAMA, 2005.

SILVA FILHO, J. F. A danação do trabalho: organização do trabalho e sofrimento psíquico. Rio de Janeiro: Te Corá, 1997.

VARGAS, V. Participação política das mulheres no século que comę̧a. In:__Cadernos de Crítica Feminista. Recife: SOS CORPO, Instituto Feminista para a Democracia. Ano III, n. 2, p. 108-135, dezembro, 2009.

WITKOSKI, Antonio Carlos. Terras, Florestas e Aguas de Trabalho: os camponeses amazônicos e as formas de uso de seus recursos naturais. Manaus: EDUA, 2007. 